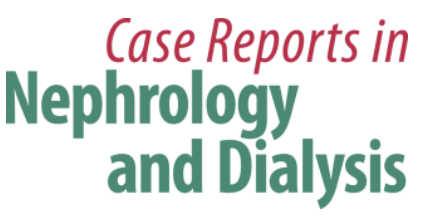

Case Rep Nephrol Dial 2018;8:171-177

DOI: 10.1159/000491631

Published online: August 10, 2018

(c) 2018 The Author(s)

Published by S. Karger AG, Basel www.karger.com/cnd

This article is licensed under the Creative Commons Attribution-NonCommercial 4.0 International License (CC BY-NC) (http://www.karger.com/Services/OpenAccessLicense). Usage and distribution for commercial purposes requires written permission.

\title{
Acute Kidney Injury after Pembrolizumab-Induced Adrenalitis and Adrenal Insufficiency
}

\author{
Ramy M. Hanna ${ }^{a} \quad$ Umut Selamet $^{a}$ Patrick Bui ${ }^{b}$ Shih-Fan Sun ${ }^{b}$ \\ Olivia Shenouda ${ }^{a} \quad N_{i l o o f a r}$ Nobakht $^{\mathrm{a}}$ Marina Barsoum ${ }^{\mathrm{a}}$ Farid Arman ${ }^{\mathrm{a}}$ \\ Anjay Rastogi ${ }^{a}$ \\ aDivision of Nephrology, Department of Medicine, UCLA David Geffen School of \\ Medicine, Los Angeles, CA, USA; ${ }^{b}$ Department of Medicine, UCLA David Geffen School of \\ Medicine, Los Angeles, CA, USA
}

\section{Keywords}

Pembrolizumab - Adrenalitis - Adrenal insufficiency - Immune checkpoint inhibitor therapy · PD-1 · PD-L1 · CTL-4 inhibitors · Acute kidney injury · Acute tubular necrosis

\begin{abstract}
Pembrolizumab is an immune checkpoint inhibitor that targets the programmed cell death protein 1 (PD-1) antigen and induces an immune response against tumor tissues. It has been successful in inducing remission in patients with severe metastatic disease, often refractory to other chemotherapeutic agents. The risk of injury of other organ systems has been noted with reported cases of glomerular disease and endocrine disease. In addition, hypophysitis as well as dermatological and gastroenterological side effects have been reported. Renal injury with immune checkpoint inhibitors like nivolumab and pembrolizumab is usually mediated via interstitial nephritis, though glomerular disease presentations like anti-neutrophil cytoplasmic antibody-associated vasculitis, immune complex disease, and thrombotic microangiopathy have also been reported. We report a 70-year-old Caucasian male who underwent treatment
\end{abstract}




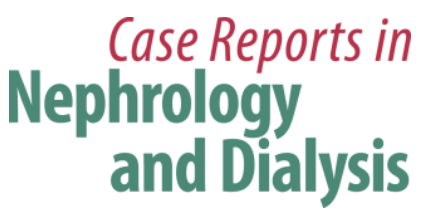

\begin{tabular}{l|l} 
Case Rep Nephrol Dial 2018;8:171-177 \\
\hline DOI: 10.1159/000491631 & $\begin{array}{l}\text { @ } 2018 \text { The Author(s). Published by S. Karger AG, Basel } \\
\text { www.karger.com/cnd }\end{array}$
\end{tabular}

with pembrolizumab for adenocarcinoma of the lung. He developed acute adrenal insufficiency and concomitant severe hypotension upon presentation. He did not require renal replacement therapy, rather his severe acute kidney injury resolved with hydration, normalization of blood pressures with vasopressors, and treatment with high-dose corticosteroids. His urinary indices (fractional excretion of urea, FEUrea) and clinical course were highly suspicious for acute tubular necrosis that resolved quickly after treating his underlying adrenalitis. The urinary sediment, proteinuria, and clinical course were not typical for the usually expected renal lesion of interstitial nephritis in patients treated with immune checkpoint inhibitors.

(C) 2018 The Author(s)

Published by S. Karger AG, Basel

\section{Introduction}

Pembrolizumab (Keytruda ${ }^{\odot}$; Merck, Kenilworth, NJ, USA) is a monoclonal antibody made by targeting programmed cell death protein 1 (PD-1) antigen. It has been used for monotherapy and combination therapy against a variety of malignant targets. The mechanism is thought to be related to selective silencing of immunological cell surface protein that protects healthy and tumor cells from induction of apoptosis by the immune system [1]. The use of immune checkpoint inhibitors has been related to the manifestation of adverse events related to in advertent autoimmune disease given the targeting of a self/nonself recognition antigen like PD-1. These agents have been associated with hypophysitis [2], immune complex renal disease [3], thrombotic microangiopathy (TMA) [4], acute interstitial nephritis (AIN) [5, 6], dermatological manifestations (vitiligo) [7], and autoimmune-induced endocrinopathies [8], especially autoimmune adrenal insufficiency $[9,10]$.

It is important to note that endocrinopathies and renal dysfunction have been documented in the literature previously with immune checkpoint inhibitor use [11]. The general mechanism of renal dysfunction after immune checkpoint inhibitor treatment usually involves autoimmune glomerular disease or less specific acute tubulo-interstitial nephritis [12, $13,14]$. More unusual examples of renal disease include TMA, minimal change disease, immune complex glomerulonephritis, and drug-induced lupus from immune checkpoint inhibitors [15-18]. These agents include anti-PD-1, anti-programmed cell death protein ligand 1 (PD-L1), and anti-cytotoxic T-lymphocyte antigen 4) (CTL-4) inhibitors. See Table 1 for the known cases of glomerular disease and interstitial disease reported with the use of immune checkpoint inhibitors such as pembrolizumab. Endocrinopathies have other renal-related manifestations, such as hyponatremia in pembrolizumab [6] and autoimmune adrenalitis/adrenal insufficiency in nivolumab use [2].

Rates of acute kidney injury (AKI) has been reported to vary widely depending on the immune checkpoint inhibitor used and the series reporting the AKI (2-13.9\%) [4, 6, 10-14]. Though glomerular disease has been more popularly reported, other causes of AKI presented in the above reviews may have occurred due to other reasons. Hemodynamic changes due to adrenal insufficiency are certainly capable of disrupting normal renal function, and this presents yet another way AKI could occur without inflammatory glomerulonephritis.

We present a case of a 70-year-old Caucasian male with adenocarcinoma of the lung who presented with severe hypotension and was confirmed to have severe adrenal insufficiency, 


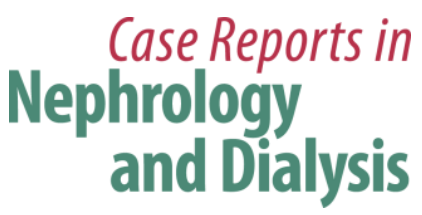

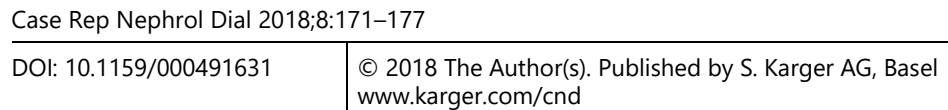

type II myocardial infarction, and AKI due to pembrolizumab injection. The cause of the AKI was thought to be acute tubular necrosis (ATN) by clinical presentation, urinary electrolytes, and rapid improvement in clinical course. Additionally, the urine studies did not show an active sediment suggestive of AIN or acute tubulointerstitial nephritis (ATIN). Given the rapid improvement with drug withdrawal and corticosteroid replacement, a renal biopsy was not sought and the patient was not rechallenged with the immune checkpoint inhibitor.

\section{Case Report}

The patient presented is a 70-year-old Caucasian male with a history of alcohol overuse, essential hypertension, peripheral arterial disease, coronary artery disease after a non-ST elevation myocardial infarction (NSTEMI), with a 3-vessel coronary artery bypass graft in 2014. Historically, he had a preserved ejection fraction and a St. Jude bioprosthetic aortic valve replacement inserted in 2014. He developed metastatic stage IV adenocarcinoma of the lung and was started on pembrolizumab by his oncologist with an initial favorable response.

He presented to the emergency department with severe hypotension with systolic blood pressure in the range of 50-70 mm Hg, a history of increased fatigue, weight gain, and weakness. His troponin was found to be $2.8 \mathrm{ng} / \mathrm{mL}$, his serum creatinine was $7.2 \mathrm{mg} / \mathrm{dL}$, his blood urea nitrogen was $78 \mathrm{mg} / \mathrm{dL}$, his serum bicarbonate level was $21 \mathrm{mmol} / \mathrm{L}$, and sodium and potassium were within the normal limits. His baseline serum creatinine was usually between 1 and $1.2 \mathrm{mg} / \mathrm{dL}$ without known proteinuria. His hematological parameters were abnormal but did not vary from his baseline, with his platelets generally ranging between 30,000 and $100,000 / \mu \mathrm{L}$. He was given fluid resuscitation with $30 \mathrm{~mL} / \mathrm{kg}$ bolus, and upon checking a random serum cortisol level it was found to be $1.4 \mu \mathrm{g} / \mathrm{dL}$ (normal range $>10.99 \mu \mathrm{g} / \mathrm{dL}$ ). A cardiac echo revealed an acute drop in cardiac function with an ejection fraction decrease from 55$60 \%$ to $35 \%$ without evidence of wall motion abnormalities, right heart strain, or cardiac tamponade.

The patient's labs and medications were reviewed, and there were no other nephrotoxic exposures. The angiotensin receptor blocking agent (losartan) used for hypertension control was stopped. Specifically, the patient denied drugs, herbal medications, or nonsteroidal antiinflammatory drug use. There was no evidence of recent administration of bisphosphonates or intravenous computed tomography/angiographic iodinated contrast. Nephrological workup was pursued; a renal ultrasound did not show hydronephrosis and a Foley catheter was inserted to ensure strict collection of any urine output. Since the patient was on a statin, a creatine phosphokinase level was drawn and was only marginally elevated at $277 \mathrm{U} / \mathrm{L}$ (normal range $<171 \mathrm{U} / \mathrm{L}$ ).

Urinalysis showed $1+$ blood (after Foley insertion) and 1+ protein but the urine protein to creatinine ratio was only $0.06 \mathrm{~g}$ total protein/g creatinine. This mismatch may have indicated the presence of free myoglobin (heme pigment). There was no other active sediment apart from the 1+ blood on routine urine analysis; there were $0-5$ red blood cells/high-power field, and 0-5 white blood cells/high-power field. Given the chronicity of the platelet drop TMA was deemed unlikely, but a review of patient's peripheral smear did not show schistocytes. 


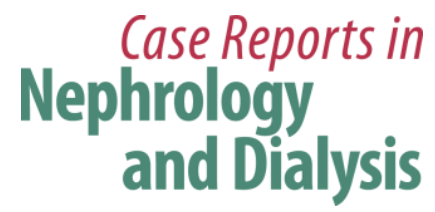

\begin{tabular}{l|l} 
Case Rep Nephrol Dial 2018;8:171-177 \\
\hline DOI: 10.1159/000491631 & $\begin{array}{l}\text { (c) } 2018 \text { The Author(s). Published by S. Karger AG, Basel } \\
\text { www.karger.com/cnd }\end{array}$
\end{tabular}

Hanna et al.: Renal Injury after Pembrolizumab-Induced Adrenalitis and Adrenal Insufficiency

There was also no elevation of direct or indirect hyperbilirubinemia to suggest hemolysis. Hemoglobin was $10.2 \mathrm{mg} / \mathrm{dL}$, white blood cell count was $5,100 / \mu \mathrm{L}$, and platelets were low at $77,000 / \mu \mathrm{L}$ but within earlier baseline levels mentioned above.

A calculated fractional excretion of urea (FEUrea) was 46\%, suggesting ATN/intrarenal disease. Urine sodium and fractional excretion of sodium (FENa) could not be used as they are typically not accurate in sodium-losing endocrinopathies like adrenal insufficiency. After hydration, vasopressor administration with norepinephrine, and starting stress dose steroid dexamethasone $5 \mathrm{mg}$ intravenously 3 times a day, the patient's blood pressure improved and he was able to maintain a mean arterial pressure $>60 \mathrm{~mm} \mathrm{Hg}$. Over the next $72 \mathrm{~h}$ the patient's serum creatinine declined from 7.2 to $1.3 \mathrm{mg} / \mathrm{dL}$ and copious urine output was made as the patient entered the post-ATN diuresis phase of ATN recovery. A cosyntropin stimulation test showed an increase from baseline cortisol level of $8.4 \mu \mathrm{g} / \mathrm{dL}$ to a cortisol level of $12 \mu \mathrm{g} / \mathrm{dL}$ after injection. The sluggish rise in serum cortisol confirmed the underlying diagnosis of adrenal insufficiency and adrenalitis was suspected given the acute onset of symptoms. The cause of the cardiomyopathy was unknown but was not pursued further as the patient opted to avoid invasive procedures and discontinue chemotherapy, and elected hospice care after his recovery. See Figure 1 for plot of serum creatinine versus date in this case. The platelets are plotted to show stability to confirm that there was no evidence of a TMA or systemic complement dysregulation to explain the episode of AKI.

\section{Discussion}

The diagnosis of adrenalitis, adrenal insufficiency, and ATN were established clinically in this case. The rapid resolution of symptoms negated the need for a renal biopsy to investigate etiology further. The findings we present show that hemodynamic factors caused by a rare but reported endocrinopathy caused by immune checkpoint inhibitors can be an additional source of risk for AKI in patients treated with anti-CTL4, anti PD-1, and anti PD-L1 inhibitors. It is important to keep adrenal insufficiency/adrenalitis on the differential diagnosis of patients with AKI in the setting of cancer immunotherapy. This is in addition to the predominantly seen lesion of AIN, granulomatous AIN, and the various reported rare glomerulopathies seen with these novel therapies.

\section{Statement of Ethics}

This article does not contain any studies with human participants or animals performed by any of the authors.

\section{Disclosure Statement}

The authors have no conflicts of interest to report in relation to this paper. 


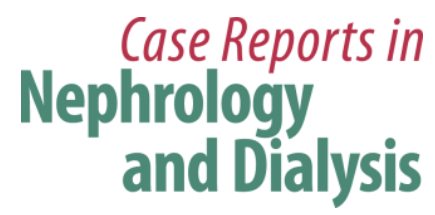

Case Rep Nephrol Dial 2018:8:171-177

DOI: $10.1159 / 000491631$

(C) 2018 The Author(s). Published by S. Karger AG, Basel www.karger.com/cnd

Hanna et al.: Renal Injury after Pembrolizumab-Induced Adrenalitis and Adrenal Insufficiency

\section{Author Contributions}

Ramy M. Hanna, MD, wrote the manuscript. Umut Selamet, MD, Patrick Bui, MD, and ShihFan Sun, MD, co-wrote the manuscript. Olivia Shenouda, MD, Niloofar Nobakht, MD, and Farid Arman, MD, edited the text. Marina Barsoum, BS, edited the table containing a review of the literature. Anjay Rastogi, MD, $\mathrm{PhD}$, is the senior author of the group and edited the text.

\section{References}

1 Raedler LA. Keytruda (Pembrolizumab): First PD-1 Inhibitor Approved for Previously Treated Unresectable or Metastatic Melanoma. Am Health Drug Benefits. 2015 Mar;8:96-100

2 Min L; LeMin. Immune-related endocrine disorders in novel Immune checkpoint inhibition therapy. Genes Dis. 2016 Dec;3(4):252-6.

3 Jung K, Zeng X, Bilusic M. Nivolumab-associated acute glomerulonephritis: a case report and literature review. BMC Nephrol. 2016 Nov;17(1):188.

4 Cortazar FB, Marrone KA, Troxell ML, Ralto KM, Hoenig MP, Brahmer JR, Le DT, Lipson EJ, Glezerman IG, Wolchok J, Cornell LD, Feldman P, Stokes MB, Zapata SA, F. Hodi S, Ott PA, Yamashita M, Leaf DE. Clinicopathological features of acute kidney injury associated with immune checkpoint inhibitors. Kidney Int. 2016;90:638-47.

5 Escandon J. Peacock S, Trabolsi A, Thomas DB, Layka A, Lutzky J. Interstitial nephritis in melanoma patients secondary to PD-1 checkpoint inhibitor. J Immunother Cancer. 2017 Jan;5:3.

6 Wanchoo R, Karam S, Uppal NN, Barta VS, Deray G, Devoe C et al.; Cancer and Kidney International Network Workgroup on Immune Checkpoint Inhibitors. Adverse Renal Effects of Immune Checkpoint Inhibitors: A Narrative Review. Am J Nephrol. 2017;45(2):160-9.

7 Sanlorenzo M, Vujic I, Daud A, Algazi A, Gubens M, Luna SA, et al. Pembrolizumab Cutaneous Adverse Events and Their Association With Disease Progression. JAMA Dermatol. 2015 Nov;151(11):1206-12.

8 Rossi E, Sgambato A, De Chiara G, Casaluce F, Losanno T, Sacco PC et al. Endocrinopathies induced by immune-checkpoint inhibitors in advanced non-small cell lung cancer. Expert Rev Clin Pharmacol. 2016;9(3):419-28.

9 Paepegaey AC, Lheure C, Ratour C, Lethielleux G, Clerc J, Berthart J, Kramkimel N, Groussin L. Polyendocrinopathy Resulting from Pembrolizumab in a Patient with a Malignant Melanoma. J Endocr Soc 2017 Apr;1(6):646-649.

10 Michot JM, Bigenwald C, Champiat S, Collins M, Carbonnel F, Postel-Vinay S, et al. Immune-related adverse events with immune checkpoint blockade: a comprehensive review Eur J Cancer. 2016 Feb;54:139-148.

11 Linardou H, Gogas H. Toxicity management of immunotherapy for patients with metastatic melanoma. Ann Transl Med. 2016 Jul;4(14):272.

12 Murakami N, Motwani S, Riella LV. Renal complications of immune checkpoint blockade. Curr Probl Cancer. 2017 Mar - Apr;41(2):100-10.

13 Cortazar FB, Marrone KA, Troxell ML, Ralto KM, Hoenig MP, Brahmer JR et al. Clinicopathological features of acute kidney injury associated with immune checkpoint inhibitors. Kidney Int. 2016 Sep;90(3):638-47.

14 Belliere J, Meyer N, Mazieres J, Ollier S, Boulinguez S, Delas A, Ribes D, Faguer S. Acute interstitial nephritis related to immune checkpoint inhibitors. Br J Cancer. 2016 Dec;115:1457-61.

15 Fadel F, Karoui K, Knebelmann B. Anti-CTLA4 Antibody-Induced Lupus Nephritis. N Engl J Med. 2009;361(2):211-2.

16 Kidd JM, Gizaw AB. Ipilimumab-associated minimal-change disease. Kidney Int. 2016 Mar;89(3):720.

17 Bickel A, Koneth I, Enzler-Tschudy A, Neuweiler J, Flatz L, Früh M. Pembrolizumab-associated minimal change disease in a patient with malignant pleural mesothelioma. BMC Cancer. 2016 Aug;16(1):656.

18 Jung K, Zeng X, Bilusic M. Nivolumab-associated acute glomerulonephritis: a case report and literature review. BMC Nephrol. 2016 Nov;17(1):188. 


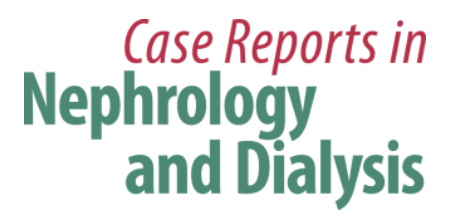

Case Rep Nephrol Dial 2018:8:171-177

DOI: $10.1159 / 000491631$

(c) 2018 The Author(s). Published by S. Karger AG, Basel www.karger.com/cnd

Hanna et al.: Renal Injury after Pembrolizumab-Induced Adrenalitis and Adrenal Insufficiency

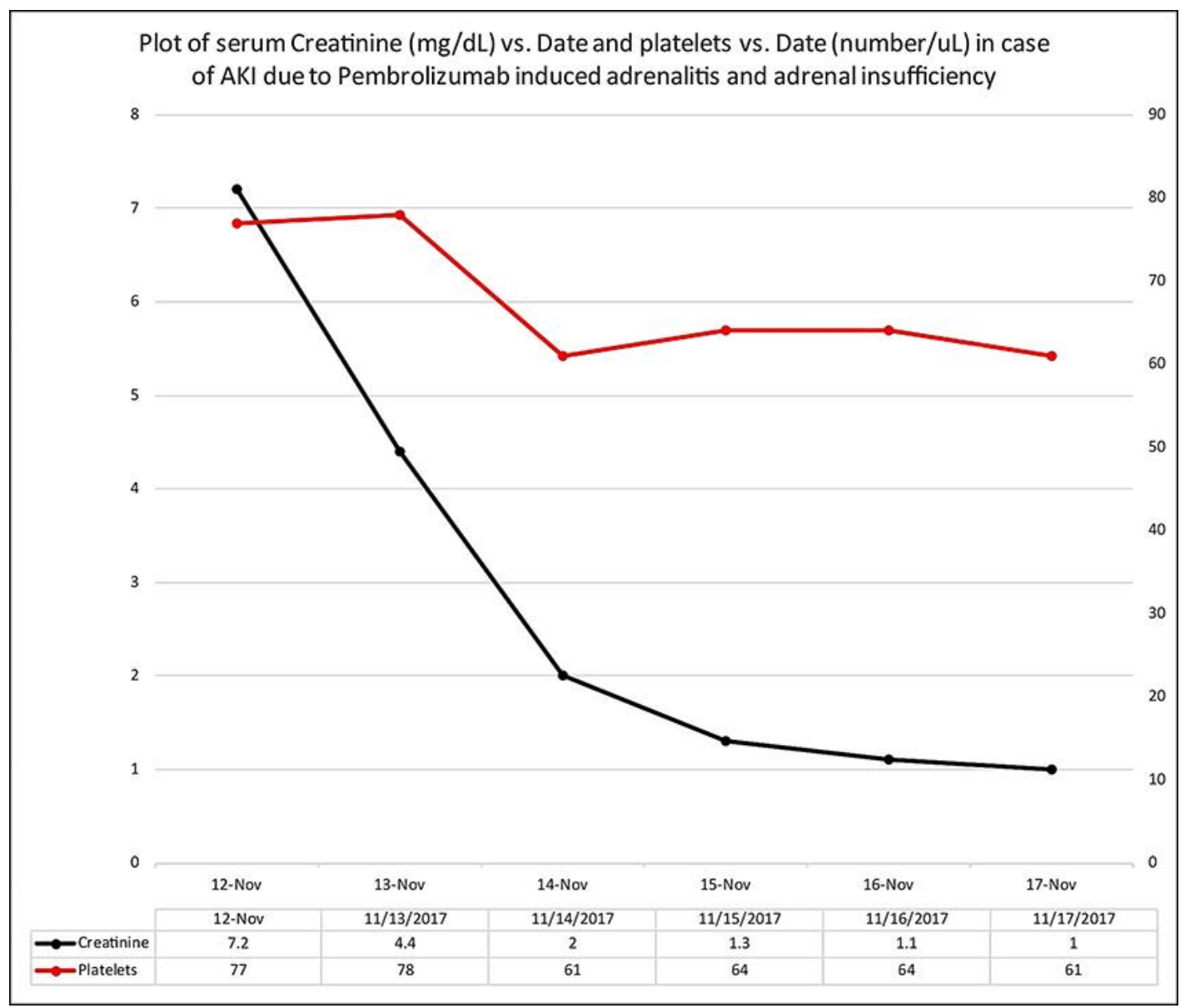

Fig. 1. Plot of serum creatinine $(\mathrm{mg} / \mathrm{dL})$ versus date and platelets versus date $(n / \mu \mathrm{L})$ in the case of acute kidney injury due to pembrolizumab-induced adrenalitis and adrenal insufficiency. 

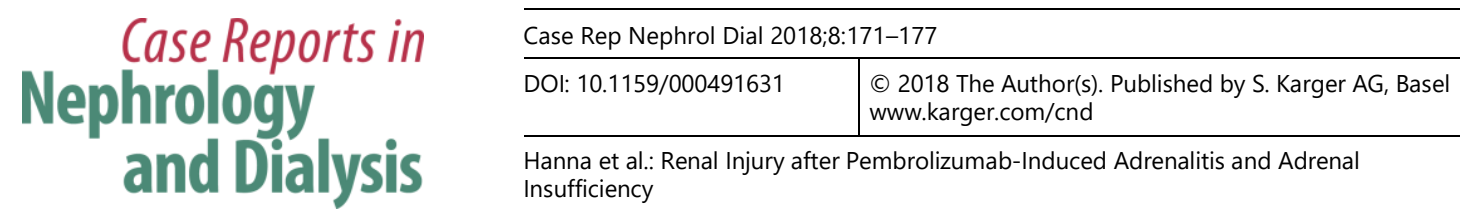

Table 1. Known cases of kidney injury and glomerular disease with immune checkpoint inhibitors

\begin{tabular}{lllll}
\hline Glomerular disease diagnosis & $\begin{array}{l}\text { Age, } \\
\text { years }\end{array}$ & Gender & Agent & Ref. No. \\
& 64 & male & ipilimumab & 15 \\
Lupus nephritis (1 case) & 55 & male & ipilimumab & 16 \\
Minimal change disease (1 case) & 58 & male & ipilimumab & 13 \\
Thrombotic microangiopathy (1 case) & 62 & male & pembrolizumab & 17 \\
Minimal change disease (1 case) & 70 & male & nivolumab & 18 \\
Immune complex glomerulonephritis (1 case) & - & - & ipilimumab & 6 \\
Renal transplant rejection (4 cases) & - & - & variable & $12-14$ \\
Acute interstitial nephritis (27 cases) & - & - & variable & 12,13 \\
Acute interstitial nephritis with granulomatous & $\quad$ & & & \\
$\quad$ features (8 cases) & 70 & male & pembrolizumab & this case \\
$\quad \begin{array}{l}\text { Presumed ATN due to hypotension from } \\
\quad \text { adrenalitis (1 case reported) }\end{array}$ & & & & \\
\hline
\end{tabular}

